\title{
PPAR- $\gamma$ agonist pioglitazone affects rat gouty arthritis by regulating cytokines
}

\author{
R.-C. Wang and D.-M. Jiang \\ Department of Orthopedics, \\ The First Affiliated Hospital of Chongqing Medical University, Chongqing, China \\ Corresponding author: D.-M. Jiang \\ E-mail: jdm571026@vip.163.com
}

Genet. Mol. Res. 13 (3): 6577-6581 (2014)

Received January 8, 2013

Accepted July 7, 2013

Published August 28, 2014

DOI http://dx.doi.org/10.4238/2014.August.28.2

\begin{abstract}
The objective was to study peroxisome proliferatoractivated receptor gamma (PPAR $\gamma)$ agonist pioglitazone regulation effect and its mechanism of expression of cytokines on acute gouty arthritis synovial in rats. Rats with unilateral ankle were injected with artificial monosodium urate (MSU) crystals to make the acute gouty arthritis model. Taking the synovium $48 \mathrm{~h}$ after the injection of MSU and using RT-PCR, we assessed the effect of pioglitazone (20 $\mathrm{mg} \cdot \mathrm{kg}^{-1} \cdot \mathrm{day}^{-1}$, oral administration) on synovial expression, by detecting tumor necrosis factor- $\alpha$ (TNF- $\alpha$ ), interleukin-1 $\beta$ (IL-1 $\beta$ ), and interferon- $\gamma$ (IFN- $\gamma)$. The pioglitazone treatment group showed synovial expression of TNF- $\alpha$, and IFN- $\gamma$ was significantly lower than in the control group; the inhibition rates were 78.5 and $60.4 \%$. The IL-1 expression difference was not statistically significant between the two groups. Pioglitazone has anti-inflammatory effects on acute gouty arthritis by inhibiting the expression of TNF- $\alpha$ and IFN- $\gamma$.
\end{abstract}

Key words: Peroxisome proliferator-activated receptor; Interleukin; Tumor necrosis factor- $\alpha$; Rats 


\section{INTRODUCTION}

Gout is caused by acute and chronic inflammatory reactions due to monosodium urate (MSU) crystal precipitation in vivo. Acute gouty arthritis is a typical clinic feature of gout (Pascual and Pedraz, 2004). Peroxisome proliferator-activated receptor gamma (PPAR- $\gamma$ ) is a ligand-dependent nuclear receptor. The PPAR- $\gamma$ agonist pioglitazone is widely used in the treatment of type 2 diabetes to improve insulin resistance. Studies have shown strong antiinflammatory effects of PPAR- $\gamma$ activation (Oates et al., 2002). Insulin resistance is the central link of metabolic syndrome, which includes gout (Fam, 2002), and pioglitazone can reduce animal acute gouty inflammation (Huang et al., 2005a,b; Kushnarenko and Govorin, 2012), but its anti-inflammatory mechanism is still unclear. To this end, the present study aimed to explore the effects of pioglitazone on synovial expression of a variety of cytokines, and to explore the possible mechanisms of gouty arthritis effect of pioglitazone.

\section{MATERIAL AND METHODS}

\section{Experimental animals}

Second level male Wistar rats $(240 \pm 15 \mathrm{~g})$ were reared and provided by the experimental animal center of the First Affiliated Hospital of Chongqing Medical University.

\section{Acute gouty arthritis model}

MSU crystals and acute gouty arthritis rat models were prepared according to a previous report (Huang et al., 2005b).

\section{Animal grouping}

Twelve rats were randomly divided into a model group and pioglitazone treatment group, 6 rats in each group. Another 6 normal rats were used to detect cytokine-inherent expression without any treatment. Pioglitazone was homogenously suspended in $1 \%$ sodium carboxymethyl cellulose, and rats were administered pioglitazone orally at a dose of $20 \mathrm{mg} \cdot \mathrm{kg}^{-1} \cdot \mathrm{day}^{-1}, 3$ days before inducing model, once daily, on 5 consecutive days. Model control group rats were given the same volume of $1 \%$ sodium carboxymethyl cellulose suspension in the same manner.

\section{Reverse transcriptase-polymerase chain reaction (RT-PCR) detection of synovial cytokine expression}

Forty-eight hours after the injection with MSU, tibial tarsal joints were opened using ophthalmic scissors and a scalpel blade by shearing along the bone surrounding the synovium and its surrounding tissues. The excised specimen was quickly washed in phosphate-buffered saline and immediately put into a tissue homogenizer with $1 \mathrm{~mL}$ TRIzol reagent to extract total RNA. RT-PCR was performed to detect the amount and purity of the RNA obtained, using a $20-\mu \mathrm{L}$ final volume, containing $3 \mu \mathrm{g}$ RNA, to produce a $20-\mu \mathrm{L}$ sample of cDNA. Primer sequences and PCR conditions used are listed in Table 1 (Huang et al., 2007). 
Table 1. Primer sequences and PCR conditions.

\begin{tabular}{lllc}
\hline Gene & Accession No. & Primers & Products (bp) \\
\hline TNF- $\alpha$ & X66539 & Sense: 5'-GTCGTAGCAAACCACCAAG-3' & 214 \\
IFN- $\gamma$ & Anti-sense: 5'-GGTATGAAGTGGCAAATCG-3' & 318 \\
IL-1 $\beta$ & SM_138880 & Ansi-sense: 5'-TGTGCTGCTAGATAGTGTG'3' & 311 \\
& M98820 & Sense: 5'-TCTGTGACTCGTGGGATG-3' & 31 \\
\hline
\end{tabular}

\section{Statistical methods}

Results are reported as means $\pm \mathrm{SD}$. The groups were compared for variance homogeneity using the Student $t$-test and the approximate $t$-test for unequal variances. The SPSS version 11.5 statistical software was used (SPSS, Chicago, IL, USA).

\section{RESULTS}

\section{Modeling success rate}

The incidence rate of MSU-induced arthritis in rats with the acute gouty arthritis model in this experiment was $100 \%$.

\section{Normal synovial cytokines inherent expression}

The normal synovial contained only a trace level of expression of TNF- $\alpha(0.009 \pm$ $0.011)$, IFN- $\gamma(0.009 \pm 0.003)$, and no IL-1 $\beta$ expression was observed.

\section{Impact of arthritis synovial cytokine expression by pioglitazone treatment}

Forty-eight hours after articular injection of MSU crystal-induced arthritis, the synovial expression of various cytokines was increased to varying degrees; the increases of TNF- $\alpha$ and IL-1 $\beta$ were particularly evident. The pioglitazone treatment group showed synovial expression of TNF- $\alpha$ and IFN- $\gamma$ significantly lower than in the control group; the inhibition rates were 78.5 and $60.4 \%$, respectively. The IL-1 $\beta$ expression was not statistically different between the two groups (Table 2).

Table 2. Cytokines expression in each group $(\mathrm{N}=6$; means $\pm \mathrm{SD})$.
\begin{tabular}{lccc}
\hline Groups & TNF- $\alpha$ & IFN- $\gamma$ & IL-1 $\beta$ \\
\hline Control group & $0.702 \pm 0.184$ & $0.141 \pm 0.037$ & $0.481 \pm 0.065$ \\
Treatment group & $0.142 \pm 0.033$ & $0.043 \pm 0.026$ & $0.297 \pm 0.102$ \\
P value & $<0.01$ & $<0.01$ & $>0.05$ \\
\hline
\end{tabular}

\section{DISCUSSION}

The fundamental causes of acute gouty arthritis are hyperuricemia and the precipitation 
of MSU crystals in local joints. MSU crystals lead to prevalent inflammatory cell infiltration, which promptly leads to severe joint pain, swelling, and dysfunction. The duration of a single arthritis episode includes 3 phases: early rapid progress, peak period, and spontaneous remission (Pascual and Pedraz, 2004). In this experiment, the MSU-induced arthritis rate was $100 \%$, showed a sharp arthritis, reaching a peak within $12 \mathrm{~h}$, and after 5-6 days, the pain underwent spontaneous remission. The results showed that the animal model fully simulated the pathogenesis of human acute gouty arthritis. Our report is in line with a previous study (Huang et al., 2007).

In the present study, we found that the monokines TNF- $\alpha$ and IL- $1 \beta$ as well as lymphokine IFN- $\gamma$ were involved in the pathological process of gout (Weinberger and Pinkhas, 1980; Pascual and Pedraz, 2004). In the present study, we also found that the normal synovial contained only a trace expression of these cytokines, while $48 \mathrm{~h}$ after MSU-induced arthritis, varying degrees of increased expression of these cytokines, particularly TNF- $\alpha$ and IL- $1 \beta$, increased significantly, consistent with the results reported in the literature.

PPAR $-\gamma$ is mainly expressed in the adipose tissue but is also expressed in monocytes/ macrophages, lymphocytes, fibroblasts, and chondrocytes (Oates et al., 2002). The main function of PPAR- $\gamma$, a member of the nuclear receptor superfamily, is regulation of gene expression at the mRNA level. Activated PPAR- $\gamma$ can reduce experimental rheumatoid arthritis (Cuzzocrea et al., 2003), osteoarthritis (Kobayashi et al., 2005), and human psoriatic arthritis (Bongartz et al., 2005). The anti-inflammatory effects of PPAR- $\gamma$ agonists may be realized through competitive binding coactivators and inhibition of NF- $\mathrm{kB}$ and AP-1 transcription factor activity (Oates et al., 2002). The research team demonstrated clear anti-inflammatory effects of the PPAR- $\gamma$ agonist pioglitazone on rat gouty arthritis, but the effects required a large dose, and the mechanism may involve promotion of macrophage maturation and function transformation (Huang et al., 2005a,b; Kushnarenko and Govorin, 2012). The experimental results showed that pioglitazone significantly inhibited the expression of rat gouty arthritis synovium of TNF- $\alpha$, and inhibited the expression of IFN- $\gamma$. However, the role of IL- $1 \beta$ is unclear. IFN- $\gamma$ is a representative Th1/Th2 cytokine, Th1 is an advanced cytokine that can aggravate arthritis. In contrast, Th2 advanced cytokines can reduce arthritis (Finnegan et al., 1999). The results suggest that inhibition of the expression of TNF- $\alpha$ and modified Th1/Th2 balance to favor Th2 is one important mechanism of the anti-inflammatory effect of pioglitazone.

\section{REFERENCES}

Bongartz T, Coras B, Vogt T, Scholmerich J, et al. (2005). Treatment of active psoriatic arthritis with the PPAR ligand pioglitazone: an open-label pilot study. Rheumatology 44: 126-129.

Cuzzocrea S, Mazzon E, Dugo L, Patel NS, et al. (2003). Reduction in the evolution of murine type II collagen-induced arthritis by treatment with rosiglitazone, a ligand of the peroxisome proliferator-activated receptor $\gamma$. Arthritis Rheum. 48: 3544-3556.

Fam AG (2002). Gout, diet, and the insulin resistance syndrome. J. Rheumatol. 29: 1350-1355.

Finnegan A, Mikecz K, Tao P and Glant TT (1999). Proteoglycan (aggrecan)-induced arthritis in BALB/c mice is a Th1type disease regulated by Th2 cytokines. J. Immunol. 163: 5383-5390.

Huang HG, Han XH, Han CG, Yuan GS, et al. (2005a). The role of pioglitazone, an agonist of the peroxisome proliferatoractivated receptor $\gamma$, in the resolution of monosodium urate monohydrate crystal-induced inflammations. Chin. J. Rheumatol. 9: 463-468.

Huang HG, YF Sun and Hu M (2005b). Rats with acute gouty arthritis model and characteristics. Milit. Med. Sci. 29: 538-542.

Huang HG, Wang ZJ, Zhang YB, Shi HY, et al. (2007). Effects of pioglitazone on cytokine expressions in synovium in rats with acute gouty arthritis. Tianjin Med. J. 35: 124-126. 
Kobayashi T, Notoya K, Naito T, Unno S, et al. (2005). Pioglitazone, a peroxisome proliferator-activated receptor $\gamma$ agonist, reduces the progression of experimental osteoarthritis in guinea pigs. Arthritis Rheum. 52: 479-487.

Kushnarenko NN and Govorin AV (2012). The alterations in fatty acids content of membranes of erythrocytes and insulin resistance syndrome under primary gout. Klin. Lab. Diagn. 17-19.

Oates JC, Reilly CM, Crosby MB and Gilkeson GS (2002). Peroxisome proliferator-activated receptor $\gamma$ agonists: potential use for treating chronic inflammatory diseases. Arthritis Rheum. 46: 598-605.

Pascual E and Pedraz T (2004). Gout. Curr. Opin. Rheumatol. 16: 282-286.

Weinberger A and Pinkhas J (1980). A hypothesis on the possible role of interferon in the initiation of acute gouty arthritis attack. Med. Hypotheses 6: 781-784. 